\title{
Arte e metáforas contemporâneas para pensar infância e educação*
}

\author{
Luciana Gruppelli Loponte \\ Universidade Federal do Rio Grande do Sul, Faculdade de Educação
}

Uma frase de Deleuze, no livro Crítica e clínica (1997), é como uma pérola perdida entre tantos outros discursos circulares que tentam falar de arte e infância, de arte e educação: “A arte [...] atinge esse estado celestial que já nada guarda de pessoal nem de racional. À sua maneira, a arte diz o que dizem as crianças" (p. 78). Que estado celestial é esse que a arte e as crianças compartilham? De que modo a arte diz o que as crianças dizem? Talvez fosse mesmo esse o mote que eu procurava para iniciar o debate aqui sobre arte, educação e infância. É isso: de algum modo, de alguma forma, a arte diz, pinta, canta, dança, imagina, fantasia o que dizem as crianças. $\mathrm{Ou}$ melhor, poderíamos dizer que o modo com o qual a arte diz coisas sobre a vida e o mundo tem a ver com o modo com o qual as crianças dizem, com que interpretam esse mesmo mundo. Talvez seja por isso que não entendemos, na maioria das vezes, o que a arte

\footnotetext{
* Faço um agradecimento especial a Mário Alberto Macha-
} do, pela indicação de obras de várias artistas citadas neste artigo e especialmente pela intermediação do pedido de autorização dos direitos de imagem da artista polonesa Ella Jablónska. diz? Ou, tampouco, o que a criança diz? Mas, afinal, há algo para entender? Por que sempre nos acompanha essa insistente "vontade de verdade" sobre as coisas? Deixemos, apenas por enquanto, a frase de Deleuze como pano de fundo.

Neste trabalho, procuro discutir a relação entre arte, educação e infância a partir das seguintes questões: de que forma podemos saber mais sobre a infância a partir de metáforas da arte contemporânea? O que a arte contemporânea pode dizer para a docência da infância? De que modo a docência vê a infância e sua arte? Podemos pensar em uma dimensão estética da formação docente para a infância? Na esteira dessas questões, debato também sobre o lugar da arte nas políticas públicas para educação infantil, especialmente no que diz respeito à formação docente e à ampliação do ensino fundamental para nove anos.

\section{Arte contemporânea e infância}

O que sabemos sobre artes visuais? A maioria das pessoas ainda vê as artes visuais com um olhar renascentista, buscando nas imagens a verdade reconhecível de paisagens, naturezas-mortas, flores, re- 
tratos, cenas diversas. O que reconhecemos, de algum modo, nos reconforta, apazigua. É assim que a arte contemporânea e a própria arte moderna ainda causam certo estranhamento a olhos pouco acostumados com imagens desconcertantes, que não remetem a nenhuma referência do nosso "arquivo de verdades" já tão conhecido. As abstrações de Miró e as distorções de Picasso, por exemplo, muitas vezes inquietam: mas, afinal, o que isso quer dizer? E a arte contemporânea? Rompendo com as fronteiras de materiais, técnicas e temas, a arte chamada contemporânea coloca em dúvida todas as nossas pretensas certezas sobre o que é (ou que deveria ser) arte:

De início, parece que, quanto mais olhamos, menos certeza podemos ter quanto àquilo que, afinal, permite que as obras sejam qualificadas como "arte", pelo menos de um ponto de vista tradicional. Por um lado, não parece haver mais nenhum material particular que desfrute do privilégio de ser imediatamente reconhecível como material de arte: a arte recente tem utilizado não apenas tinta, metal e pedra, mas também ar, luz, som, palavras, pessoas, comida e muitas outras coisas. Hoje existem poucas técnicas e métodos de trabalho, se é que existem, que podem garantir ao objeto acabado a sua aceitação como arte. (Archer, 2001, p. ix)

E o que professoras sabem sobre arte contemporânea? $\mathrm{Ou}, \mathrm{o}$ que professoras de educação infantil e anos iniciais podem saber sobre arte contemporânea? Como professora de arte em um curso de pedagogia, tive algumas experiências que me fazem acreditar na potencialidade da formação em arte para essas futuras professoras. Enquanto em grande parte das escolas infantis ainda vigora o repertório imagético infantilizado de Xuxa, Hello Kitty, Mônica e assemelhados (Cunha, 2005a, 2005b), além dos desenhos estereotipados para colorir, brindados pelos livros didáticos adotados (muitas vezes, alegremente) pelas docentes, penso que a aproximação com o mundo das artes visuais, e em especial com a arte contemporânea, pode ampliar os modos de ver a arte, as imagens que nos rodeiam e, de alguma maneira, as imagens produzidas por crianças.
Ao visitar a Bienal de Artes Visuais do MERCOSUL ${ }^{1}$ com minhas alunas de pedagogia, tive o prazer de vê-las, orgulhosamente, debatendo arte contemporânea com os mediadores, sorvendo cada detalhe, com os olhos brilhando ao depararem-se com as obras dos artistas que já haviam conhecido antes por meio de pesquisas. Essas alunas, futuras professoras de educação infantil e de anos iniciais, até pouco antes dessa experiência, acreditavam que arte era, no máximo, a Mona Lisa de Leonardo da Vinci, e que os desenhos das crianças eram tão-somente rabiscos inúteis e sem importância. Essas futuras (e atuais) professoras estavam, aos poucos, superando aqueles comentários do senso comum que já estamos tão cansados de ouvir: "se isto é arte, então vou virar artista", "isso até meu filho pequeno faz", "me sinto burro diante dessas obras".

Se conseguimos nos despir dos nossos preconceitos diante das obras de arte que fogem aos padrões de nossos confortáveis referenciais familiares, de objetos de arte colecionáveis ou, de alguma forma, utilitários, há muito o que aprender com a arte contemporânea, ${ }^{2}$ não apenas sobre a própria arte, mas sobretudo a respeito das questões mais importantes do tempo em que vivemos, como a infância, por exemplo.

Arte e infância entrecruzam-se em vários períodos artísticos. Podemos lembrar de algumas representações de crianças desenhando, como a que aparece em um detalhe da obra $O$ atelie do artista (1855) de Gustave Courbet, ou da obra Claude desenhando, Françoise e Paloma (1954), de Pablo Picasso, conforme figuras 1 e 2 a seguir.

${ }^{1}$ V Bienal de Artes Visuais do MERCOSUL - Histórias da Arte e do Espaço, realizada em Porto Alegre de 30 de setembro a 4 de dezembro de 2005.

2 “A ausência de um objeto da galeria claramente identificável como 'obra de arte' incentiva a noção de que nós, observadores, deveríamos fazer é decidir olhar os fenômenos do mundo de um modo 'artístico'. Assim, estaríamos fazendo a nós mesmos a pergunta: 'Suponhamos que eu olhe para isto como se fosse arte. O que, então, isto poderia significar para mim?'”(Archer, 2001, p. 95). 


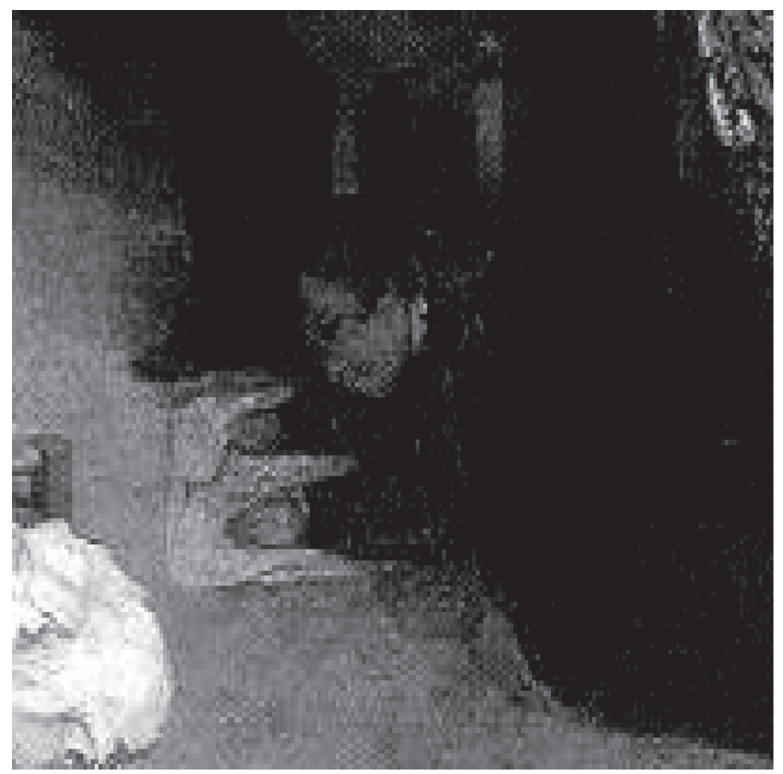

Figura 1: Detalhe de O Ateliê do Artista (1855), de Gustave Courbet

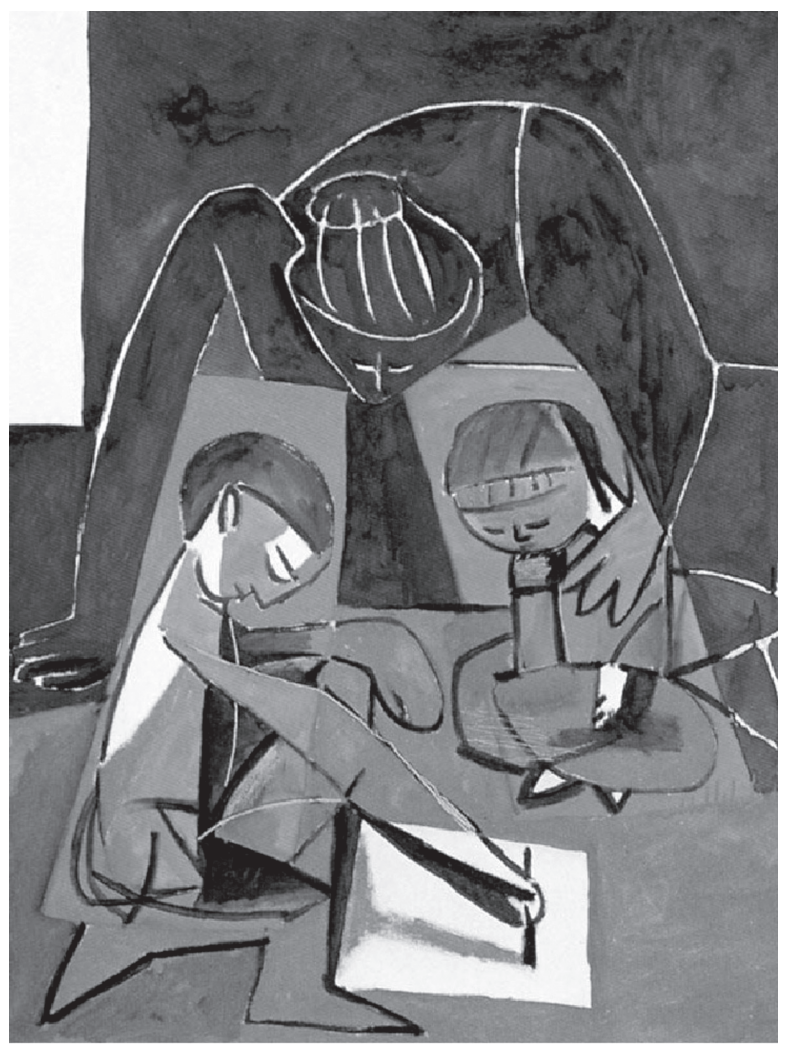

Figura 2: Claude desenhando, Françoise e Paloma (1954), Pablo Picasso

É preciso lembrar também que muitos artistas buscaram inspiração para seu trabalho na infância. As vanguardas artísticas aportaram no mundo de ima- gens infantis para trazer nova vida aos seus trabalhos. Não é à toa que as imagens coloridas e mágicas de Miró encantam tanto as crianças. E é atribuída a Picasso uma das frases que mais exaltam a arte infantil. $\mathrm{O}$ artista afirma que na sua infância era capaz de desenhar como o artista renascentista Rafael, mas precisou de toda uma existência para aprender a desenhar como uma criança. ${ }^{3}$ Ou podemos lembrar ainda, entre outros exemplos, da busca do pintor gaúcho Iberê Camargo pela arte do "pátio da infância": "no meu andarilhar de pintor fixo a imagem que se me apresenta no agora e retorno às coisas que adormeceram na memória, que devem estar escondidas no pátio da infância" (Camargo, 1998, p. 32).

Mas que figura de infância é essa, tão perseguida? É ainda forte no nosso imaginário a figura milenar da infância como "paraíso perdido", "natureza domada", "matéria-prima para fabricação de um mundo novo", "ponto zero de um processo de desenvolvimento ou de formação" (Larrosa, 2001, p. 282). É essa ainda a imagem de infância mais presente nos discursos pedagógicos. Mas talvez seja outra a imagem que lemos na angustiada busca pelo novo, ou por certa originalidade do processo criativo de alguns artistas. O elogio da infância como "atitude estética e vital" pode ser considerado suspeito, como ainda adverte Larrosa (2002, p. 121), se vivemos em uma época marcada por aparatos de infantilização maciça dos indivíduos e de produção sistemática do esquecimento. Afinal, o que esquecemos, o que deixamos para trás? O que tanto procuram os artistas na idealizada "pureza original" da infância? Sinais de cansaço, desgaste e criatividade embotada levam artistas à procura das cintilâncias da infância? E que lugar haveria para a experiência estética da infância na educação?

${ }^{3}$ A frase integral de Picasso é a seguinte: "Levamos muito tempo para nos tornarmos jovens. Quando vejo pinturas de crianças, dou-me conta de que só agora posso iniciar meu trabalho de juventude. Quando tinha a idade delas, era capaz de desenhar como Rafael... Mas levei anos para aprender a desenhar como uma criança" (Claret, 1985, p. 80). 
Ao pensar na infância fraturada, fragmentada, descontínua, tão presente nas escolas, a todo o momento escapando aos prognósticos deterministas e prescritivos de teorias psicológicas e pedagógicas de "como as crianças devem ser", penso com Larrosa na imagem de uma infância como acontecimento, que escapa a qualquer integração ou identidade: "o que não pode ser integrado, nem identificado, nem compreendido, nem previsto", ou que pode ser nomeado como "interrupção, novidade, catástrofe, surpresa, começo, nascimento, milagre, revolução, criação, liberdade" (Larrosa, 2001, p. 282). Para ilustrar essa figura da infância como acontecimento, Larrosa retoma a criança das três metamorfoses de Nietzsche. Para o filósofo alemão, essa figura de criança não é uma simples figura do passado ou a origem de algo do qual temos que nos afastar para "evoluir". O espírito-criança é o próprio por-vir, a abertura, o horizonte de um relato de libertação (idem, p. 283). Ouçamos um pouco o próprio Nietzsche (2003):

Inocência é a criança, e esquecimento; um novo começo, um jogo, uma roda que gira por si mesma, um movimento inicial, um sagrado dizer "sim".

Sim, meus irmãos, para o jogo da criação é preciso dizer um sagrado "sim": o espírito agora quer a sua vontade, aquele que está perdido para o mundo conquista o seu mundo.

Nomeei-vos três metamorfoses do espírito: como o espírito tornou-se camelo e o camelo, leão e o leão, por fim, criança. (p. 53)

Enquanto o camelo é o animal dócil, domesticado, servil, obediente, que segue o rebanho, o leão aparece como um espírito crítico, rebelde, que heroicamente luta por sua liberdade, de força negativa, a encarnação do espírito ressentido e niilista, o próprio sujeito moderno. A criança, por sua vez, surge como esquecimento, inocência, jogo, afirmação, criação, abertura, possibilidade, início (Larrosa, 2002, p. 110). E aqui vale sublinhar uma das afirmações de Larrosa no mesmo texto (p. 118): o outro nome da criança de "As três metamorfoses" de Nietzsche é criação. Po- deríamos dizer que, para Nietzsche, a criação é força impulsionadora para a própria vida, pura potência, afirmação da vida que está aqui, não a negação desta vida em relação a uma vida mais verdadeira que está em outro lugar.

Se para Nietzsche não há uma "origem", ${ }^{4}$ não há então uma essência a se descobrir, uma verdade a encontrar, uma unidade perdida a retomar. Há, sim, "o infinito desdobramento, a constante transformação, a proliferação de sentidos, a criação" (Mosé, 2005, p. 36). Aí surge a vontade de potência, a vontade de criação que se contrapõe à "vontade de verdade" do homem moderno. A arte, mais do que algo feito por artistas ou especialistas, ou como instituição e como obra, é, para o filósofo alemão, uma atividade propriamente criadora, uma força artística presente não somente no homem, mas em todas as coisas (idem, p. 79). Poderíamos assim pensar na infância e na arte como forças potencialmente criadoras, poéticas da própria vida? Há que se pensar nos modos como a infância e a arte têm sido "pedagogizadas", "didatizadas", "controladas" pela docência e pelas escolas. Por que ainda queremos crianças-camelo, queremos ensiná-las a obedecer, a cumprir ordens, ver o que queremos que ela veja (Fischer, 2006)? Estamos mesmos perdidos em meio ao esquecimento de nossas possibilidades criadoras, apartados que estamos da arte e da infância?

Esta incursão filosófica permite-nos ainda pensar no impensado da infância nas teorias educacionais mais tradicionais. Uma infância concebida

\footnotetext{
${ }^{4}$ Em um texto bastante conhecido, Foucault (2001) trata jus-
} tamente da recusa do genealogista Nietzsche em buscar uma suposta origem da história, ou por empreender uma pesquisa da origem: "Procurar uma tal origem é tentar reencontrar 'o que era imediatamente', o ‘aquilo mesmo' de uma imagem exatamente adequada a si; é tomar por acidental todas as peripécias que puderam ter acontecido, todas as astúcias, todos os disfarces; é querer tirar todas as máscaras para desvelar enfim uma identidade primeira. [...] A razão? Mas ela nasceu de uma maneira inteiramente ‘desrazoável' - do acaso”' (p. 18). 
como acontecimento não é passível de discursos prescritivos ou de controle, aprisionada em um tempo linear e progressivo. Uma infância cujas palavras-chave são criação, invenção, descontinuidade, subversão:

A criança não é nem antiga nem moderna, não está nem antes nem depois, mas agora, atual, presente. Seu tempo não é linear, nem evolutivo, nem genético, nem dialético, nem sequer narrativo. A criança é um presente inatual, intempestivo, uma figura do acontecimento. E só a atenção ao acontecimento, como o incompreensível e o imprevisível, pode levar a pensar uma temporalidade descontínua. (Larrosa, 2001, p. 284)

E são a descontinuidade e a imprevisibilidade algumas das principais matérias-primas com as quais lida a arte contemporânea. Rupturas de espaço e tempo, questionamento de verdades, desequilíbrio, o novo, o inesperado. A arte contemporânea é feita da irrupção de acontecimentos. Nem sempre há molduras ou paredes para abrigar quadros, nem sempre as obras se apresentam na perspectiva tradicional a que estamos acostumados. As obras podem ser interativas, podem ser tocadas, sentidas ou modificadas pelos espectadores, ou nada disso. Unidade, coerência e identidade de temas, técnicas e materiais distanciamse muitas vezes dessa arte. Talvez esteja um pouco aí a razão da dificuldade de aproximação com esse modo contemporâneo de ver e produzir imagens, se estamos ainda marcados pela estabilidade, fixidez e linearidade com que aprendemos a interpretar o mundo. Aprendemos, modernos que somos, a ambicionar um mundo-verdade, um mundo sem contradições, sem mutação, sem luta, sem dor.

E como pensar essa figura de infância como acontecimento por meio da arte contemporânea? Se ainda vemos resquícios nostálgicos de uma infância idealizada nas produções de artistas modernos, as artes visuais hoje nos trazem inúmeras metáforas para pensar sobre outras infâncias. É importante ressaltar o quanto as mulheres artistas, muitas vezes ainda ausentes das listas de "grandes artistas", e que em gran- de parte vivem a experiência da infância ${ }^{5}$ bem de perto, produzem representações que escapam aos modos de ver mais comuns. Algumas imagens criadas por mulheres artistas rompem com os lugares estereotipados destinadas a elas pela cultura, e com nossas idéias mais antigas sobre o que é (ou pode ser) o feminino. Artistas contemporâneas, principalmente a partir dos anos de 1990, surpreendem cada vez mais ao romperem com padrões chamados "femininos", reciclando e reinventando acervos materiais e simbólicos constituintes do universo feminino há muito tempo. Mais do que revelarem com suas obras uma suposta "essência" ou "identidade" de mulheres, mostram com seus trabalhos justamente a impossibilidade da busca de uma unidade. "Não existe nada no fato de ser 'mulher' que naturalmente una as mulheres", provoca Donna Haraway (2000, p. 52). ${ }^{6}$ E, acrescentaria, nem mesmo as concepções que as mulheres, mães ou não, têm sobre a infância.

\footnotetext{
${ }^{5}$ Ao escrever sobre a questão complexa das relações de gê-
} nero e a primeiríssima infância, Faria (2006) lembra o quanto as experiências femininas são marcantes para a instituição de escolas de educação infantil. Se em um primeiro momento a luta por creche era principalmente uma demanda das mulheres que precisavam trabalhar, mais tarde passou também a ser reivindicada como um direito das crianças de 0 a 6 anos por educação. A história da creche é diferente da história da escola, articulando um direito à educação das crianças pequenas com o direito trabalhista de pais e mães.

${ }^{6}$ Para que, afinal, precisamos de uma identidade? Identidade ou afinidade? Sobre as identidades fragmentadas e as lutas feministas por identidade, Donna Haraway é contundente: “A existência de uma dolorosa fragmentação entre as feministas (para não dizer 'entre as mulheres'), ao longo de cada fissura possível, tem feito com que o conceito de mulher se torne escorregadio: ele acaba funcionando como uma desculpa para a matriz das dominações que as mulheres exercem umas sobre as outras. Para mim - e para muitas outras mulheres que partilham de uma localização histórica similar (corpos brancos, de classe média profissional, femininos, de esquerda, estadunidense, de meia-idade) - as fontes dessa crise 
A infância, aos olhos da mãe-artista, pode ser um comovente desenho da filha sobre um travesseiro bordado, como o fez a artista gaúcha Paula Mastroberti. ${ }^{7}$

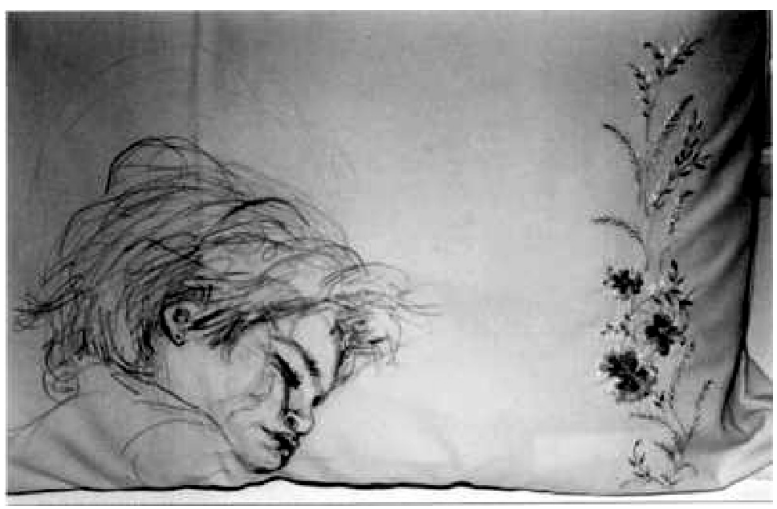

Figura 3: Júlia, Paula Mastroberti, 2001.

A fragmentação (e destruição) de um dos brinquedos infantis mais antigos, a boneca, também pode ser uma forma de tematizar a infância. Nas construções e criações da artista brasileira Lia Menna Barreto ${ }^{8}$ as bonecas transformam-se ao serem mutiladas, costuradas e derretidas, desafiando nossa mais doce compreensão do universo infantil. Nem sempre a infância é doce e alegre, ela também é desvio, perversão, manipulação. E é dessa mesma artista uma das imagens e metáforas mais contundentes sobre as instituições infantis. A instalação Jardim da infância, presente na I Bienal de Artes Visuais do MERCOSUL, realizada em 1997, apresenta 11 cadeiras infantis em círculo (Catálogo, 1997, p. 231). As cadeiras estão queima-

de identidade política são incontáveis. A história recente de grande parte da esquerda e do feminismo estadunidense tem sido construída a partir das respostas a esse tipo de crise - respostas que são dadas por meio de infindáveis cisões e de buscas por uma nova unidade essencial. Mas existe também um reconhecimento crescente de uma outra resposta: aquela que se dá por meio da coalizão - a afinidade em vez da identidade" (2000, p. 53).

${ }^{7}$ Sobre outras obras da artista, ver o site http://www. mastroberti.art.br.

${ }^{8}$ Ver mais sobre as obras da artista em http://www.artewebbrasil. com.br/artistasconvidados/Lia/textoscriticos.htm das e quebradas, tão mutiladas quanto as bonecas de outros trabalhos da artista. Que infância é essa que habita esse círculo melancólico?

A infância presente nas obras de Laura Ford, ${ }^{9}$ artista do País de Gales, é uma infância que choca, que desafia, que amedronta. Na instalação Headthinkers, vemos em uma sala branca uma série de esculturas feitas de cerâmica e plástico em tamanho natural, vestidas com roupas comuns, como qualquer criança vestiria. Imagens de crianças com cabeças de burro, melancolicamente penduradas pelas paredes, ajoelhadas, apoiadas por suas estranhas cabeças. Alguma semelhança com as antigas (e atuais) punições escolares? Talvez. O que, afinal, pensam essas crianças?

Paula Rego é uma das artistas portuguesas mais importantes da atualidade. Suas imagens muitas vezes são desconcertantes. Família (1988) traz uma cena familiar pouco comum. O homem chega em casa e é ajudado (ou sufocado? torturado?) pela filha e pela esposa. Uma menina de olhar cúmplice assiste à cena, emoldurada pela luminosidade da janela, dando um tom mais dramático à narrativa pictórica. No retábulo ao fundo, uma suposta imagem de São Jorge lutando contra um dragão. O homem está sendo dominado, como o dragão? A infância pode ser perversa? Quem sabe. ${ }^{10}$

Para terminarmos, por enquanto, nosso passeio por algumas imagens de infância produzidas pela arte contemporânea, trago as provocações da artista polonesa Ella Jablónska às nossas mais "sagradas" noções de maternidade. Na série de fotografias Supermother (Supermatka, 2006) ${ }^{11}$, a artista apresenta-se como uma mãe-heroína, ora vestida com roupas de Super-Homem, ora como Homem-Aranha ou Batman. O cenário: a cozinha, a sala ou o quarto de uma casa simpática e agradável, extremamente limpa

${ }^{9}$ Sobre Laura Ford e a exposição Headthinkers: http:// www.re-title.com/artists/laura-ford.asp.

${ }^{10}$ Para saber mais sobre Paula Rego, ver http://library. thinkquest.org/17016/frames.htm.

${ }^{11}$ Sobre a série de Ella Jablónska: http://free.art.pl/ galeria.artmix/ela/ej/sm.htm. 
e bem cuidada. No colo da Supermãe, o filho, tal como uma "pietá" pós-moderna. A cena remete-nos às madonas pintadas inúmeras vezes ao longo da história da arte ocidental, sacralizando e cristalizando na figura da mãe de Jesus a própria imagem da maternidade. Longe do campo do sagrado, o que a infância contemporânea exige das mulheres (mães e professoras)?

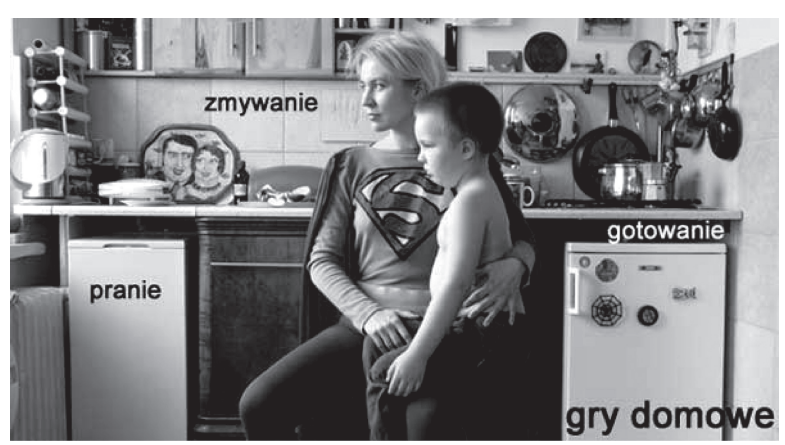

Figura 4: Jogos domésticos, da série Supermother, Ella Jablónska, 2006.

Um pequeno percurso apenas por algumas imagens da arte contemporânea. $\mathrm{O}$ que aprendemos com elas? Sem buscar sínteses ou conclusões, que talvez sejam desnecessárias aqui, o importante é perceber a dissonância da própria infância, da impossibilidade de aprisioná-la em rótulos, clichês ou temporalidades predefinidas. A arte é feita de possibilidade, de invenção, de criação, de ruptura, do imprevisível, do inesperado. A infância, também, é puro acontecimento. E o que a docência para a infância pode aprender com a arte? Quais as nossas metáforas contemporâneas para pensar a educação para a infância?

\section{Arte, docência e infância}

As palavras "acontecimento", "descontinuidade", "abertura" ainda soam estranhas quando associadas à infância escolarizada das instituições infantis. Embora a arte seja um terreno fértil para a abertura e possibilidade, a escola consegue aprisioná-la em tempos e espaços específicos, em imagens controladas com pouco espaço para os rabiscos imaginários da infância.

A docência na educação infantil é ainda, em grande parte, o terreno do improviso. Usa-se a "intuição feminina", muitas vezes ligada a um pressuposto instinto materno, que faria parte de uma "essência" característica de todas as mulheres. Cuidar, trocar fraldas, velar o sono, alimentar, deixar brincar à vontade fazem parte da rotina diária das escolas infantis. A arte infantil nem sempre é entendida ou se destina um espaço privilegiado para ela. Ou melhor, justamente pela ansiedade em entender ou descobrir a "verdade" dos desenhos infantis é que há pouco espaço para eles. Enquanto a arte moderna rompeu com os limites das representações figurativas já no início do século $\mathrm{XX}$, muitas professoras ainda se sentem inconformadas diante de rabiscos aparentemente sem sentido. Exploração do papel, registro do gesto, ludicidade? Para quê? É assim que os rabiscos e as invenções infantis precisam sempre ser nomeados, legendados: "O que você desenhou aqui?". A criança responde, e a professora escreve sobre o desenho: legendas e rótulos definitivos competindo visualmente com as criações infantis. A escrita da professora no desenho certifica, dá status de "verdadeiro" ao trabalho. Aqui é o papai, a mamãe, o cachorro, ou o que for. É como não se admitisse nunca que a criança seja ainda um in-fante, aquele que não fala, que não tem linguagem. E linguagem aqui entendida como o lugar da unidade, identidade, como signo do rebanho, como critica Nietzsche (Mosé, 2005). Como se fosse preciso necessariamente abandonar esse estado de "não-fala". Mas por que essa in-fância precisa ser abandonada, banida da experiência humana?

A idéia de uma infância como uma "substância psíquica" pré-subjetiva revela-se então um mito, como aquela de um sujeito pré-lingüístico, a infância e linguagem parecem assim remeter uma à outra em um círculo no qual a infância é a origem da linguagem e a linguagem a origem da infância. Mas talvez seja justamente neste círculo que devemos procurar o lugar da experiência enquanto infância do homem. Pois a experiência, a infância que aqui está em questão, não pode ser simplesmente algo que precede cronologicamente a linguagem e que, a uma certa altura, cessa de existir para versar-se na palavra, não é um paraíso que, em determinado momento, abandonamos para sempre a fim 
de falar, mas coexiste originalmente com a linguagem, constitui-se aliás ela mesma na expropriação que a linguagem dela efetua, produzindo a cada vez o homem como sujeito.

(Agamben, 2005, p. 59)

Para Agamben, a experiência, no seu sentido mais profundo, tão escassa nos tempos atuais, não pode estar inscrita apenas na linguagem, na palavra: "Que o homem não seja sempre já falante, que ele tenha sido e seja ainda in-fante, isto é a experiência" (idem, p. 62). Não seria também a arte esse lugar da experiência da in-fância, essa experiência humana da qual o sujeito moderno da linguagem e da palavra insiste em se afastar? Talvez a insistente busca pela coesão da linguagem e sua unidade, pela capacidade de relacionar palavras e coisas, por dar sentido, pela premência em abandonar o estado de infância e "não-fala" nos tenha impedido de viver a vida mais esteticamente, de experienciar o jogo, a criação, a afirmação da vida que tantas vezes dançam alegremente através da infância e da arte. Qual é, afinal, a função da linguagem? Seguindo o caminho aberto por Agamben, ou mesmo antes, por Nietzsche, e aqui com ajuda de Viviane Mosé (2005), podemos pensar que a função da linguagem "não é aproximar o eternamente separado, mas produzir esta ponte que torna capaz de dançar sobre as distâncias que constituem as coisas". Ou ainda: "A função afirmativa da linguagem não é dizer, já que a complexidade da vida não pode ser reduzida em palavras. A função da linguagem é sobrevoar, dançar, fazer esquecer" (p. 128). E não é isso mesmo que faz a arte?

Um diálogo travado com uma professora em um curso de formação docente traz mais elementos para pensar sobre essas questões. A professora pergunta, preocupada: "o que eu devo fazer se meu aluno pintar um gato de azul?”. Há na pergunta aquele medo de estar fazendo algo errado, de que é preciso sempre saber e dizer o "real" sentido de tudo, e a crença de que a escola jamais poderá iludir a criança e que sempre deverá contar toda a verdade sobre as coisas, mesmo que a verdade seja a mais "cruel" de todas: não existem gatos azuis. Claro que um artista como o brasileiro Aldemir Martins não acreditava nisso e foi o criador de muitos gatos azuis, vermelhos, amarelos, sem pensar se eles realmente existiam ou não. É disso mesmo que é feita a arte: de invenção, criação, imaginação que vai bem mais além do que cremos ser a realidade. A arte talvez seja feita da matéria de uma experiência e linguagem que dançam e sobrevoam os sentidos das coisas, sem se preocupar se há mesmo uma verdade a que se deva bater continência. Mas quem sabe disso? Ou quem pensa sobre isso? Poucas professoras de educação infantil sabem ou dedicam algum tempo para pensar sobre questões como essas. E não há por que culpá-las. A formação em arte da maioria das pessoas ainda é muito precária. As professoras são frutos dessa mesma escola que valorizou demasiadamente a aprendizagem da leitura, da escrita e da matemática ou uma determinada racionalidade, em detrimento de outras formas de conhecer e pensar sobre o mundo, como as artes visuais, a música, o teatro e a dança.

Afastados da arte, estamos ainda muito apegados à "vontade de verdade" do homem moderno, que, para Nietzsche, aniquila a vontade de criação. Para o filósofo, esse "amor à verdade" é apenas mau gosto, um desvario adolescente que o aborrece. Tudo é aparência, não há verdades a descobrir, essências a desvendar. E é aí que ele nos convoca a assumir uma postura artística diante da vida, que não nos deixemos dominar pela vontade de verdade, por uma desenfreada ansiedade de atingir a essência das coisas, mas que nos deixemos tomar por uma vontade de potência, pela vontade de reinventar o real, de transfigurar a própria vida (Loponte, 2003).

\section{Quando as políticas (e os livros didáticos) não dançam: que lugar há para arte e infância?}

Mas o que alimenta, afinal, a docência para a infância? De que modo a docência vê a infância e sua arte? Podemos pensar assim nos próximos desdobramentos diante das novas políticas públicas para infância no Brasil, e como a docência está implicada nisso. A ampliação para nove anos do ensino fundamental, com a inclusão da criança aos 6 anos nesse 
sistema de ensino, significará a diminuição da infância? A inclusão da criança de 6 anos de idade (e, às vezes, de cinco anos) no $1^{\circ}$ ano do ensino fundamental significará o seu ingresso definitivo no mundo da palavra e o abandono da in-fância? Que lugar terá a arte, essa experiência nem sempre traduzível em palavras? ${ }^{12}$ Ou melhor, que "arte" estará ali? A arte "escolarizada" dos livros didáticos, pautada por desenhos estereotipados e datas comemorativas?

Acredito que não há como pensar em políticas para a infância sem pensar na docência e no que a alimenta, no que a forma. Enquanto há um incremento das pesquisas sobre educação infantil e em formação docente no país, em muitas escolas infantis são alguns livros didáticos que tomam o lugar de "especialistas da infância". Coleções de livros como "Alfabetização sem segredos", ${ }^{13}$ dirigidos ao ensino in-

${ }^{12}$ Apesar de estar previsto nos Referenciais Curriculares Nacionais para a Educação Infantil ( $\mathrm{RCN})$ o trabalho com arte com crianças de 0 a 6 anos, é preocupante perceber que documento do Ministério da Educação (MEC) referente ao Programa de Formação Inicial para Professores em Exercício na Educação Infantil (PROINFANTIL) (Brasil, 2005) não contemple essa área em seus eixos e desdobramentos principais: Linguagens e Códigos, Matemática e Lógica, Identidade, Sociedade e Cultura e Vida e Natureza. O curioso é que o documento, acessível pelo site do Ministério da Educação (www.mec.gov.br), é todo ilustrado com desenhos "pretensamente" infantis. Paradoxalmente, no documento sobre os parâmetros de qualidade para a educação infantil é esperado que as propostas pedagógicas das instituições contemplem, entre outros, princípios estéticos, "no que se refere à formação da criança para o exercício progressivo da sensibilidade, da criatividade, da ludicidade e da diversidade de manifestações artísticas e culturais" (Brasil, 2006, p. 31). Mas, em que momento há espaço para a formação estética dos docentes que atuam na educação infantil?

${ }^{13}$ Esta é uma publicação da editora IEMAR, de Contagem (MG), de autoria de Maria Radespiel (2002), que se apresenta como "seguidora das idéias de Piaget e Vygotsky". A coleção "Alfabetização sem Segredos - Educação Infantil" é composta de nove volumes para o maternal (Coleção Pirulito), nove volumes para o $1^{\circ}$ período (Coleção Cata-Vento), nove volumes para o fantil, circulam em profusão em muitas escolas infantis da região de Santa Cruz do Sul, por exemplo. Essas coleções são vendidas pelas editoras diretamente nas escolas e têm exercido um apelo irresistível às docentes, pouco acostumadas a livrarias. A referida coleção apresenta livros para todas as faixas etárias da educação infantil, desde o maternal, utilizando chamadas que dão certo tom "oficial" a essas publicações: "trabalhando de acordo com os RCN (MEC)". A coleção utiliza-se de todo o discurso legitimado pelo MEC, pelo RCN. Em relação à arte, por exemplo, falase em artes visuais ou linguagem visual, música e teatro, inclusive com trechos literais dos documentos oficiais. Enquanto aparentemente há um discurso pedagógico supostamente "moderno", legitimado pela linguagem oficial, o conteúdo é exatamente o mesmo de qualquer cartilha tradicional. Atividades para colorir ou colar papel picado, com legendas de cores predeterminadas, desenhos estereotipados para colorir relativos às datas comemorativas, só para ficar em alguns exemplos. As atividades e os desenhos parecem subestimar a capacidade das crianças em criar e apreciar imagens de qualidade. Como vemos o que poderíamos chamar de uma "epidemiologia de representações da infância" (Chalmel, 2004) nesses materiais didáticos? Por que as professoras se aliam e se "colam" tão facilmente a esse tipo de atividade? De que é feita a experiência da docência? Uma experiência expropriada de infância e de arte? Que papel tem a experiência estética para a formação docente?

Acredito que a docência pode ainda aprender muito com os artistas e as artistas, com a arte contemporânea, com a vontade de criação impulsionada pela arte. Podemos aprender mais sobre a infância, sobre o mundo, sobre nós mesmas como docentes. Não poderia, afinal, a docência ser uma obra de arte? Não poderíamos aprender com a arte essa vontade de sermos

$2^{\mathrm{o}}$ período, nove volumes para o pré-escolar e $1^{\mathrm{a}}$ série e dois volumes para redação na fase alfabética - faixa etária de 5 a 8 anos $1^{\circ}$ ciclo da alfabetização. Há também uma coleção dirigida para todo o ensino fundamental. 
artistas de nossa própria existência, "poetas-autores de nossas vidas", como queria Nietzsche? ${ }^{14} \mathrm{Ou}$ ainda continuar indagando com Michel Foucault: por que afinal a arte é algo apenas para especialistas? Não poderia a própria vida ser uma obra de arte? (Foucault, 1995). Daí a importância de que cursos de formação docente privilegiem a formação estética e artística das futuras docentes. ${ }^{15}$ No entanto, a dimensão estética dessa formação, é preciso dizer, não se pode restringir a disciplinas ou cursos que passeiem panoramicamente por técnicas e atividades artísticas. É preciso alimentar esteticamente as futuras docentes ${ }^{16}$ com um mergulho em experiências que as desloquem, que as perturbem, que subvertam esse modo linear e contínuo de compreender a arte e a infância. Talvez, pela arte, possamos descobrir um pouco mais dessa infância como acontecimento, da infância como legítima experiência humana, de um "devir-criança como processo criativo de uma educação que resista às vergonhas do presente" (Jódar \& Gómez, 2002, p. 43).

Já acompanhados de Nietzsche, Agamben e Larrosa no percurso deste texto, voltamos a Deleuze e à frase que abriu nossa conversação: "à sua maneira, a arte diz o que dizem as crianças". Se a arte diz mesmo o que dizem as crianças, se a arte pode nos conectar com experiências que nos transformam, que nos deslocam da linearidade de nossas paisagens familiares, se nos diz de acontecimento, de experiên-

${ }^{14}$ Ver o aforismo 299 de A gaia ciência (2001), intitulado "O que devemos aprender com os artistas". Essas questões foram desenvolvidas com mais profundidade em Loponte (2005).

${ }^{15}$ As novas diretrizes curriculares para o curso de pedagogia, aprovadas pelo MEC em maio de 2006, incluem as artes como uma das linguagens e conteúdos pertinentes aos primeiros anos de escolarização, como já é prática em muitos cursos de pedagogia no Brasil. Resta saber como esse trabalho está sendo realizado nesses cursos.

${ }^{16}$ Ver outros trabalhos que têm explorado a questão da dimensão estética na formação docente e na educação a partir de perspectivas teóricas diversas, como: Pereira (1996), Martins (1999), Leite e Ostetto (2004), Loponte (2005), Ostetto (2006), Farina (2006) e Amorim (2007). cia, de criação e, também, de infância, a pergunta é: nós, que pensamos sobre educação, sabemos ouvir?

\section{Referências bibliográficas}

AGAMBEN, Giorgio. Infância e história: destruição da experiência e origem da história. Belo Horizonte: UFMG, 2005.

AMORIM, Verussi de Mello. Por uma educação estética: um enfoque na formação universitária de professores. 2007. Dissertação (Mestrado em Educação) - Centro de Ciências Sociais Aplicadas, Pontifícia Universidade Católica de Campinas, Campinas, 2007.

ARCHER, Michael. Arte contemporânea: uma história concisa. São Paulo: Martins Fontes, 2001.

BRASIL. Ministério da Educação. Proinfantil - Programa de Formação Inicial para Professores em Exercício na Educação Infantil: diretrizes gerais. Brasília: MEC, 2005. Disponível em: <http:/ /portal.mec.gov.br/seb/arquivos/pdf/Educinf/diretrizes.pdf $>$. Acesso em: 25 maio 2007.

. Parâmetros nacionais de qualidade na educação in-

fantil. v. 2. Brasília: MEC, 2006. Disponível em: <http:// portal.mec.gov.br/seb/arquivos/pdf/Educinf/eduinfparqualvol2.pdf $>$. Acesso em: 25 maio 2007.

CAMARGO, Iberê. Gaveta dos guardados. São Paulo: EDUSP, 1998. CATÁlogo da Primeira Bienal de Artes Visuais do Mercosul. Porto Alegre: FBAVM, 1997.

CHALMEL, Loic. Imagens de crianças e crianças nas imagens: representações da infância na iconografia pedagógica nos séculos XVII e XVIII. Educação e Sociedade, Campinas, v. 25, n. 86, p. 57-74, abr. 2004.

CLARET, Martin (Coord.). O pensamento vivo de Picasso. São Paulo: Martin Claret, 1985. (coleção O pensamento vivo.)

CUNHA, Susana Rangel Vieira da. Cenários da educação infantil. Educação \& Realidade, Porto Alegre, n. 30, v. 2, p. 165-185, jul./dez. 2005a. . Um pouco além das decorações das salas de aula. Reflexão e ação, Santa Cruz do Sul, v. 13, n. 1, p. 133-149, jan./jun. 2005b. DELEUZE, Gilles. O que as crianças dizem. In: Critica e clínica. São Paulo: Ed.34, 1997. p. 73-79.

FARIA, Ana Lúcia Goulart de. Pequena infância, educação e gênero: subsídios para um estado da arte. Cadernos Pagu, Campinas, n. 26, p. 279-287, jan./jun. 2006.

FARINA, Cynthia. Pedagogia das afecções: arte atual, corpo e sujeito. Reflexão e Ação, Santa Cruz do Sul, v. 14, n. 1, p. 45-53, jan./jun. 2006. 
FISCHER, Rosa Maria Bueno. Infância, mídia e experiência. In: GURSKI, Roselene; DALPIAZ, Sonia; VERDI, Marcelo Spalding (Orgs.). Cenas da vida atual. A família, a escola e a clínica. Ijuí: Ed. UNIJUÍ, 2006. p. 27-40.

FOUCAULT, Michel. Sobre a genealogia da ética: uma revisão do trabalho. In: DREYFUS, Hubert; RABINOW, Paul. Michel Foucault, uma trajetória filosófica. Para além do estruturalismo e da hermenêutica. Rio de Janeiro: Forense Universitária, 1995. p. 253-278.

Nietzsche, a genealogia e a história. In: Microfisica do poder. Rio de Janeiro: Graal, 2001. p. 15-37.

HARAWAY, Donna. Manifesto ciborgue: ciência, tecnologia e feminismo-socialista no final do século XX. In: SILVA, Tomaz Tadeu da (Org.). Antropologia do ciborgue: as vertigens do póshumano. Belo Horizonte: Autêntica, 2000. p. 37-129.

JÓDAR, Francisco; GÓMEZ, Lucía. Devir-criança: experimentar e explorar outra educação. Educação e Realidade, Porto Alegre: FACED/UFRGS, v. 27, n. 2, p. 31-45, jul./dez. 2002.

LARROSA, Jorge. Dar a palavra. Notas para uma lógica da transmissão. In: LARROSA, Jorge; SKLIAR, Carlos. Habitantes de Babel: políticas e poéticas da diferença. Belo Horizonte: Autêntica, 2001. p. 281-295.

. Nietzsche e educação. Belo Horizonte: Autêntica, 2002.

. O enigma da infância: ou o que vai do impossível ao verdadeiro. In: . Pedagogia profana: danças, piruetas e mascaradas. Porto Alegre: Contrabando, 1998. p. 229-246.

. Do espírito da criança à criança do espírito. A idéia de formação em Peter Handke. In: Pedagogia profana: danças, piruetas e mascaradas. Porto Alegre: Contrabando, 1998b. p. $54-88$.

LEITE, Maria Isabel; OSTETTO, Luciana Esmeralda. Formação de professores: o convite da arte. In: OSTETTO, Luciana E.; LEITE, Maria Isabel. Arte, infância e formação de professores: autoria e transgressão. Campinas: Papirus, 2004. p. 11- 24.

LOPONTE, Luciana Gruppelli. Do Nietzsche trágico ao Foucault ético: sobre estética da existência e uma ética para a docência. Educação e Realidade, v. 28, n. 2, jul./dez. 2003.

Docência artista: arte, estética de si e subjetividades femininas. 2005. 207f. Tese (Doutorado em Educação) - Fa- culdade de Educação, Universidade Federal do Rio Grande do Sul, Porto Alegre, 2005.

MARTINS, Mirian Celeste. Arte: o seu encantamento e o seu trabalho na educação de educadores - a celebração de metamorfoses da cigarra e da formiga. 1999. Tese (Doutorado em Educação) Faculdade de Educação, Universidade de São Paulo, São Paulo, 1999.

MOSÉ, Viviane. Nietzsche e a grande política da linguagem. Rio de Janeiro: Civilização Brasileira, 2005.

NIETZSCHE, Friedrich. A gaia ciência. São Paulo: Companhia das Letras, 2001.

Assim falou Zaratustra. Rio de Janeiro: Civilização

Brasileira, 2003.

OSTETTO, Luciana. A arte no itinerário da formação de professores: acender coisas por dentro. Reflexão e Ação, Santa Cruz do Sul, v. 14, n. 1, p. 29-43, jan./jun. 2006.

PEREIRA, Marcos Villela. A estética da professoralidade: um estudo interdisciplinar sobre a subjetividade do professor. 1996. Tese (Doutorado em Supervisão e Currículo) - Faculdade de Educação, Pontifícia Universidade Católica de São Paulo, São Paulo, 1996.

RADESPIEL, Maria. Alfabetização sem segredos. Diário do professor. Contagem: Iemar, 2002. (Coleção Pirulito - Maternal)

LUCIANA GRUPPELLI LOPONTE, doutora em educação pela Universidade Federal do Rio Grande do Sul (UFRGS) e professora da Faculdade de Educação na mesma universidade, é vicecoordenadora do Grupo de Estudos de Educação e Arte da ANPEd. Últimas publicações: "Docência artista: arte, gênero e ético-estética docente" (Educação em Revista, n. 43, p. 35-55, jun. 2006); "Gênero, educação e docência nas artes visuais" (Educação \& Realidade, v. 30, n. 2, p. 243-259, jul./dez. 2005); "O rei não está mais aqui. E agora? Imagens de arte, poder e educação" (Revista Digital Art\&, n. 3, p. 1-9, abr. 2005). Pesquisa atual: “Arte e estética na formação docente”.E-mail: lucianagl@terra.com.br

Recebido em maio de 2007 Aprovado em julho de 2007 
Luciana Gruppelli Loponte

Arte e metáforas contemporâneas

para pensar infância e educação

Nesse trabalho é discutida a relação entre arte, educação e infância a partir 
das seguintes questões: de que forma podemos saber mais sobre a infância a partir de metáforas da arte contemporânea? O que a arte contemporânea pode dizer para a docência da infância? De que modo a docência vê a infância e sua arte? Podemos pensar em uma dimensão estética da formação docente para a infância? Na esteira dessas questões, debato também sobre o lugar da arte nas políticas públicas para educação infantil, especialmente no que diz respeito à formação docente e à ampliação do ensino fundamental para nove anos. Como interlocutores privilegiados para essa discussão, Deleuze, Nietzsche e Agamben.

Palavras-chave: dimensão estética e docência; infância; arte contemporânea e educação

\section{Art and contemporary metaphors} for reflecting on childhood and education

This paper discusses the relation between art, education and childhood by means of the following questions: how can we know more about childhood by means of contemporary art metaphors? What message could contemporary art have for teachers? How do teachers regard infancy and its art? Can we think of an aesthetic dimension of teacher training for children? On the basis of these questions, the text discusses the very place of art within public policies of child education, particularly with regard to teacher training and the recent extension of basic education in Brazil from eight to nine years. Deleuze, Nietzsche and Agamben are the privileged interlocutors for this debate.

Key words: aesthetic dimension and teaching; childhood; contemporary art and education

\section{Arte y metáforas contemporáneas para pensar en infancia y en educación}

En este trabajo es discutida la relación entre arte, educación e infancia a partir de las siguientes cuestiones: ¿de qué forma podemos saber más sobre la infancia a partir de metáforas del arte contemporáneo? ¿Qué puede decir el arte contemporáneo para la docencia de la infancia? ¿De qué modo la docencia ve la infancia y su arte? ¿Podemos pensar en una dimensión estética de formación docente para la infancia? En el rastro de esas cuestiones, debato también sobre el lugar del arte en las políticas públicas para la educación infantil, especialmente a la formación docente y a la ampliación de la enseñanza fundamental para nueve años.. Como interlocutores privilegiados para esta discusión, Deleuze, Nietzsche y Agamben.

Palabras claves: dimensión estética y docencia; infancia; arte contemporáneo y educación 